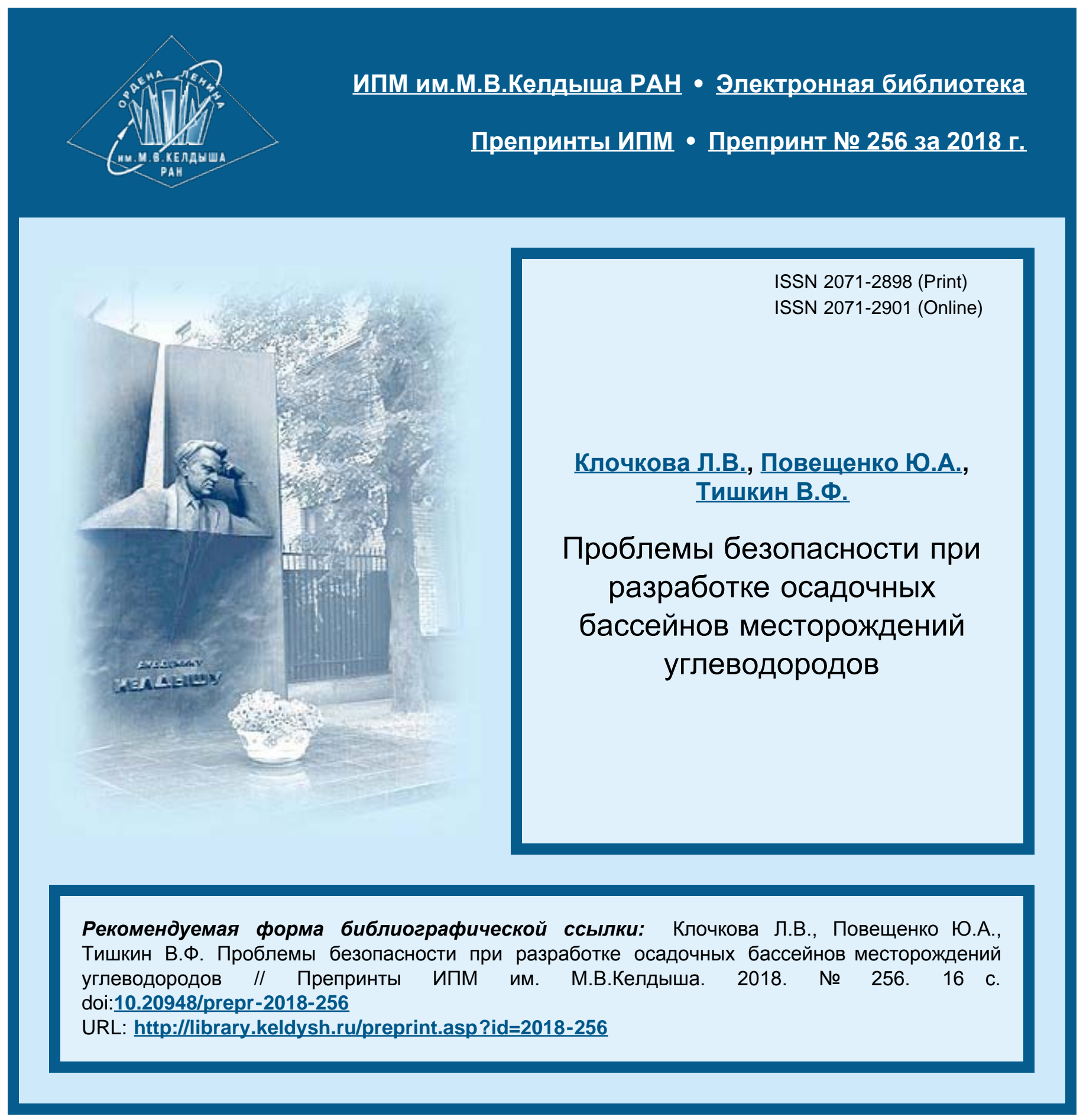




$$
\begin{gathered}
\text { О р д е н } \text { Л е н и н а } \\
\text { ИНСТИТУТ ПРИКЛАДНОЙ МАТЕМАТИКИ } \\
\text { имени М.В.Келдыша } \\
\text { Р о с и й с к й а к д е м и н а к }
\end{gathered}
$$

Л.В. Клочкова, В.Ф. Повещенко, В.Ф. Тишкин

ПРОБЛЕМЫ БЕЗОПАСНОСТИ ПРИ РАЗРАБОТКЕ ОСАДОЧНЫХ БАССЕЙНОВ МЕСТОРОЖДЕНИЙ УГЛЕВОДОРОДОВ 
Клочкова Л.В., Повещенко Ю.А., Тищкин В.Ф.

Проблемы безопасности при разработке осадочных бассейнов месторождений углеводородов

Численное моделирование движения флюидов при формировании залежей углеводородов позволило исследовать сложные автоколебательные режимы этого процесса. В данной работе излагаются результаты вычислительных экспериментов для этих режимов, проведенных на основании эмпирических данных по ряду регионов, и сделанное на этом основании заключение об их характерных свойствах.

Ключевые слюва: безопасность при разработке, осадочные бассейны, автоколебательные режимы, флюиды, углеводороды

\section{Liudmila Viktorovna Klochkova, Yuriy Andreevich Povestchenko, Vladimir Fedorovich Tishkin \\ Safety issues in the exploitation of sedimentary basins of hydrocarbon deposits}

Numerical simulation of fluid motion in the formation of hydrocarbon deposits allowed us to investigate complex self-oscillating regimes of this process. This paper presents the results of computational experiments for these models, conducted on the basis of empirical data for a number of regions, and made on this basis the conclusion about their characteristic properties

Key words: safety in the exploitation, sedimentary basins, oscillatory models, fluids, hydrocarbons

Работа выполнена при поддержке Российского фонда фундаментальных исследования (проект 17-01- 00361_а) и Госзадания: тема ФАНО №2,

Математическое моделирование в задачах гидроаэрогазодинамики: подпункт 19. Математическое моделирование задач фильтрации в пористых средах, в том числе задач нефтегазодобычи и гидрогеологии 


\section{1. Введение}

При разработке осадочных бассейнов углеводородов проблемы безопасности сопровождают человечество на протяжении всей истории технического прогресса. Особенно это касается добычи угля в глубоких шахтах угольных бассейнов. Но и при разработке открытым способом: добыче угля, газовых гидратов, сланцевой нефти и других углеводородов - та же опасность подстерегает людей. Вообще, любое вмешательство человека в недра Земли связано с опасностью взрывов, пожаров, обвалов при недостаточно изученных свойствах коллекторов. Без проведённых предварительно цифровых анализов рисков: вычислительных экспериментов с реальными геометриями осадочных бассейнов - велика опасность катастрофических последствий такого внедрения. А осадочным бассейном всех видов углеводородов, существующих в той или иной степени одновременно, является вся поверхность Земли. Такой анализ требуется и при создании ракетных комплексов в глубоких шахтах под землёй, при проведении метро, строении туннелей в новых районах страны. Сейчас в связи с потеплением и таянием вечной мерзлоты наблюдаются существенные изменения в ландшафте и вообще в экологии целых районов. Серьёзные учёные, не ангажированные политиками, выдвигают гипотезы повышения температуры на Земле из-за изменения земной орбиты. При этом оттаивание наблюдалось в последний раз сто тридцать тысяч лет назад. Но что действительно беспрецедентно, это скорость оттаивания. Если в прошлом оно происходило на протяжении тысяч лет, сейчас мы наблюдаем, что таяние происходит на несколько порядков быстрее. В нормальных условиях вечной мерзлоты регулируется количество двуокиси углерода и метана в окружающей атмосфере. Вечная мерзлота забирает и сохраняет значительную часть углеводородов. В настоящее время выделяются эти накопления углеродов, создавая парниковый эффект, что ускоряет таяние. Оттаивание уже отрицательно влияет на жизнь жителей северных районов Сибири, так как вся инфраструктура (дороги, здания) до сих пор были устойчивы благодаря мёрзлой почве. Сейчас велика опасность разрушения инфраструктуры и гибели людей, оказавшихся на бездонных болотах. Кроме того, с 2014 года на Ямале обнаружены несколько крупных воронок загадочных гигантских кратеров. Существует несколько гипотез, как образуются эти кратероподобные дыры на поверхности земли. По одной из версий: дыры образуются при прорывах с взрывом двуокиси углерода и метана. В подтверждение этой гипотезы синий снег - серьёзное предупреждение сибирякам о грозящих катастрофах. Всплывание огромных пузырей газа со дна океана приводит к образованию ловушек с пониженным давлением и провалу в них различных плавательных средств. Таким образом, развиваемые представления в рамках моделей движения флюидов из источников, находящихся глубоко под землёй, и создание математических моделей в виде системы уравнений, описывающих такие процессы (в частности, с учётом гравитации), которые обладают 
смешанным одновременно гиперболическим и параболическим типом, позволяет интерпретировать многие разнородные загадочные явления. Работы по созданию методик для цифрового анализа рисков проводятся в Институте прикладной математики им. М.В. Келдыша РАН совместно с институтами «Нефти и газа» и «Океанологии» РАН. Начало этим работам было положено несколько десятков лет назад с создания теории образования осадочных бассейнов. В последние годы были созданы программные комплексы, позволяющие наглядно представлять структуру различных коллекторов и проводить численные эксперименты на основе созданных математических моделей. Это могло бы позволить создавать поверхностные карты рисков, где видны все этапы процессов временной динамики: фазы пробоев, реверсия, релаксация. Именно анализ результатов вычислительных экспериментов позволили открыть режимы гравитационно-реверсивных колебаний масс газа. Интерпретация наблюдающихся спорадических выбросов метана в шахтах, приводящих к взрывам, образованию кратероподобных дыр и синего снега на поверхности земли может базироваться также на этих результатах. Эти вычислительные эксперименты могут даже подтвердить гипотезу о таинственных исчезновениях кораблей и самолётов: подъём со дна океанов огромных пузырей газа, под которыми могут быть полости с пониженным давлением и куда попадают плавающие или летательные аппараты.

\section{2. Математические модели}

Численное моделирование движения флюидов при формировании залежей углеводородов позволило выявить сложные автоколебательные режимы этого процесса [1,2]. При описании движения жидкостей и газов в пористой среде использованы уравнения фильтрации в предположении выполнения закона Дарси в поле силы тяжести, несмешиваемости фаз (например, газ вода), изотермичности и при пренебрежении капиллярными силами. Это сложная система нелинейных дифференциальных уравнений в частных производных. По одной из переменных - давлению - она обладает свойствами, близкими к уравнениям параболического типа, по другой водонасыщенности - гиперболическими свойствами, в том числе с образованием поверхностей разрыва - скачков насыщенности. Область, в которой решается система, обычно обладает высокой степенью неоднородности, состоит из слоев с различными коллекторными свойствами (пористостью, проницаемостью), разрывными нарушениями, литологическими неоднородностями и другими особенностями, усложняющими как сами фильтрационные процессы, так и их численное моделирование. Для изучения подобных задач большие возможности предоставляет метод опорных операторов [1,2], позволяющий использовать неструктурированную сетку с ячейками, размеры которых могут отличаться на несколько порядков. При 
численном исследовании этим методом выяснилось, что в задачах, соответствующих процессам миграции углеводородов, могут возникать автоколебательные гравитационно-реверсивные режимы. Характерный цикл протекает следующим образом: давление накопившегося газа под плохо проницаемой покрышкой в некоторый момент времени может превысить некоторое критическое значение. Тогда происходит прорыв газа, причем если это критическое давление ниже предела прочности породы, то прорыв происходит не в результате образования трещин, а из-за быстрого продвижения газа через участок даже с плохими коллекторными свойствами вследствие фильтрационной неустойчивости. Газ устремляется вверх, давление в данной области падает, возникает депрессионная воронка, что вызывает новый приток газа - до следующего достижения критического давления. Математическое моделирование взрывоопасных ситуаций базировалось на следующих процедурах:

- Изучение пространственных локализаций и параметров временной динамики углеводородных скоплений (УВ-скоплений) и зон АВПД в осадочном чехле методом моделирования фильтрационногравитационной вторичной миграции углеводородов в осадочном бассейне.

- Фильтрационно-гравитационное моделирование локализаций зон АВПД и УВ-скоплений в литологическом теле осадочных бассейнов в рамках двухфазной флюидодинамической модели вторичной миграции углеводородов.

- Моделирование временной динамики (изучение фаз и внутренней структуры колебательных циклов), а также прогнозирование развития зон АВПД и УВ-скоплений.

- Рекомендации (по результатам численного моделирования) к вскрытию и исследованию коллекторов, а также определению параметров пространственно-временной динамики скоплений УВ и давлений пластовых флюидов в зонах локализаций.

Схема происходящих процессов основывалась на представлениях последовательного продвижения газообразного флюида и заполнения ловушек. Первичным источником всех движений является горизонтальное напряжение в коре и литосфере, которое создаётся в результате глобальных геодинамических процессов, определяемых конвективными движениями в мантии. Далее глобальные процессы трансформируются в региональные движения. Решённые ранее задачи математического моделирования при создании теории образования осадочнх бассейнов могут неожиданно помочь при решении задач совершенно в других областях изучения природы реальных явлений. В теории создания осадочных бассейнов рассмотрены геомеханические модели флюидодинамических процессов с однофазным и двухфазным флюидом в 
надвигах и разломах, глубина которых превышает 7 км. На основе этих моделей исследуются условия и механизмы образования гигантских газовых и газоконденсатных месторождений в структурах типа Астраханского свода. Характерной особенностью этих структур является малая проницаемость пород вне разломов и высокая - в трещиноватых зонах. Кроме того, вся Прикаспийская впадина является гигантским углеводородным материнским телом, которое в состоянии снабдить органическим веществом все нефтеобразующие процессы в этом районе [3,4]. Поэтому сбор и переработка органического вещества может происходить в глубоких разломах, которые одновременно являются и движущей силой флюидных процессов. В разломах возникают автоколебательные процессы, обусловленные смещениями бортов разломов. Эти колебания выжимают флюиды из разломов внутрь тела надвигов, внутри которых они двигаются по ослабленным зонам. Движение двухфазного флюида в пористой среде происходит в режиме реверсивных автоколебаний, обусловленных накоплением газа в некоторых слоистых пачках. Так объясняется образование гигантских газовых месторождений, например, типа Астраханского. Предполагается, что существование автоколебательных процессов связанно с относительным смещением по бортам разлома и движением флюидов. По геофизическим данным, строение Астраханского свода характеризуется наличием как раз таких разломов. Блоки земной коры в районе вала Карпинского находятся в поле действия тектонических сил, которые приводят к движениям по разломам и сейсмическим событиям. Флюиды, попадая в очаговую зону, могут играть роль спускового крючка, т. е. создают так называемый триггерный эффект. Большинство фильтрационных моделей в разломах основывается на предположении о фильтрации углеводородов и воды сквозь упругий (или упруго-хрупкий) скелет, т.е. на модели упругой консолидации. Эти явления описываются параболическим уравнением пьезопроводности. Особенности наблюдаемого циклического процесса позволяют предположить, что изменения сейсмотектонического режима состоят из быстрых и медленных фаз. Особенности циклического процесса не укладываются в известные классы моделей и дилатантно-диффузионную концепцию. Проведён анализ математической модели подобного циклического процесса [4,5]. Фаза разжижения в разломе является медленной фазой вязкой консолидации, во время которой флюиды из очаговой зоны отжимаются в окружающий массив. В процессе этой фазы углеводороды и вода перетекают из магистральных трещин в более мелкие трещины и поры сформированного месторождения. Для описания этого процесса была предложена следующая геолого-механическая модель - модель компакции и вязкой консолидации. Два смежных блока земной коры, разделенных разломом, движутся друг относительно друга с постоянной скоростью. Границы блоков считаются плоскопараллельными, а трещиновато-пористая среда разлома - однородной, обладающей некими особыми свойствами. Поэтому краевая задача, описывающая ситуацию в 
разломе, нестационарна и одномерна по пространственной координате. Для простоты считается, что разлом ориентирован вертикально. Система трещин в разломной зоне обладает ориентацией, параллельной плоскости разлома, поэтому среда в нем анизотропна. Однако если рассматривать одномерную по пространственной координате z (ось z направлена вертикально вверх) задачу, то вертикальными смещениями скелета можно пренебречь, поскольку основные смещения границ трещин будут происходить в направлении, перпендикулярном плоскости разлома. Поэтому одномерное приближение применимо. Для описания динамики скелета для фильтрационного потока это приближение также применимо, поскольку толщина пограничного слоя для него порядка горизонтального размера трещин и, следовательно, пренебрежимо мала по сравнению с толщиной разлома, которая обычно имеет размер порядка первых километров. Результаты экспериментальных исследований, а также исследования глубинного строения земной коры показывают, что одни и те же горные породы в пределах верхней коры ведут себя по-разному в зависимости от глубины [5]. С глубиной, с увеличением всестороннего давления меняется угол между плоскостью разрушения и направлением максимального главного напряжения. Из этих экспериментов следует, что в консолидированных породах каталаз наступает на глубинах порядка 10-15 км. В ослабленных трещиноватых породах разломной зоны режим разрушения, соответствующий каталазу, наступает на меньших глубинах. По этой причине режим разрушения пород коры приводит либо к образованию листрических разломов, плавно переходящих в так называемые «коровые волноводы» [5], либо к глубинным разломам. В любом случае с глубиной увеличивается толщина разрушенной зоны.

\section{3. Модель автоколебательных процессов}

Одна из моделей автоколебательных процессов в разломной зоне состоит в том, что существуют два конкурирующих режима движения флюидов режимы компакции и дилатансии. В результате в разломе возникают две фазы цикла - дилатансионное нагружение и разгрузка, сопровождающаяся компакцией. Фаза дилатансии описывается уравнениями дилатансии Рейса. Фаза компакции описывается системой уравнений компакции, которая в безразмерной форме имеет вид [4]

$$
\frac{\partial}{\partial x}\left(f^{-l} \frac{\partial s}{\partial x}\right)=\kappa^{2} f^{-k} s-1, \quad \frac{\partial f}{\partial t}+\frac{\partial s}{\partial x}=0 .
$$

Здесь $S$ - скорость фильтрации, $f$ - пористость, $t$ - время, $\kappa^{2}-$ безразмерный параметр, равный $\kappa^{2}=\frac{H^{2}(0)}{\left(H^{*}\right)^{2}}$, где $H^{*} \equiv \sqrt{\frac{\widetilde{\zeta}^{*}}{\widetilde{\delta}^{*}}}, H(0)$-начальный $\quad$ размер $\quad$ области 
определения, $\widetilde{\zeta}^{*}, \widetilde{\delta}^{*}-$ характерные масштабы вязкости и гидравлического сопротивления среды соответственно.

Взаимодействие двух конкурирующих режимов проявляется в виде энергетически мощного автоколебательного процесса. Уравнения математической модели для описания гравитационно-реверсивных автоколебательных процессов дилатансии и компакции исследовались численно и аналитически [4,5]. При нагружении разлома в нем возникает дилатансионный эффект, связанный с раскрытием трещин. В этот момент поровое давление в разломах падает, и флюиды устремляются вниз по простиранию разлома. Расчеты показывают, что при сдвиге в режиме дилатансии в разломе возникают такие отрицательные давления, которые создают мощный эффект нагнетания флюидов в него как сверху, так и снизу. Когда движение по разлому прекращается, трещины в разломе закрываются (по крайней мере, частично) и наступает фаза компакции. Фаза компакции является более длительной и соответствует уменьшению пористости. В это время поровое давление возрастает до геостатического и даже выше. При этом флюиды частично устремляются вверх по разлому и оперяющим его трещинам, а частично - устремляются по оперяющим разломам вглубь тела надвига. Под действием этого давления раскрываются трещины в ослабленных трещиноватых зонах. Поэтому отток флюидов происходит не равномерно по всему объему, а только по ослабленным зонам.

Период автоколебаний определяется самой длительной фазой - фазой компакции. В глубоких разломах эти колебания имеют периоды порядка сотен и тысяч лет. В процессе этих колебаний флюиды будут периодически поступать из разлома в окружающие массивы. Таким образом, создаются условия для периодического "промывания" флюидами подсолевой толщи Прикаспийской впадины вплоть до глубин примерно 10-15 км.

Поскольку сверху все эти структуры перекрыты соленосными отложениями, то создаются условия для образования углеводородных месторождений. При этом указанный колебательный флюидный режим будет играть определяющую роль. Если трещиноватые зоны (по которым из разлома двигаются флюиды) перекрываются сверху непроницаемыми антиклинальными флюидоупорами, то возможно образование месторождений нефти и газа. Если же трещиноватая зона выходит на поверхность, то флюиды рассеиваются в атмосфере. Особенность модели с однофазным флюидом состоит в том, что все колебательные процессы обусловлены автоколебаниями в самом разломе. За пределами разломов движение подчиняется параболическому уравнению пьезопроводности, и решение носит типичный диссипативный характер, свойственный уравнению диффузии. Канализация миграции флюидов (которая приводит к образованию месторождений) обуславливается только наличием ослабленных сильно проводящих зон, которые упираются в непроницаемые ловушки. При этом существуют различные гидродинамические режимы. Если в рассмотренной выше схеме учесть наличие двухфазного флюида (например, 
вода газ), то помимо автоколебаний в разломе возникнут еще автоколебательные процессы в массиве пород, вмещающем разломы. Эти колебания, с одной стороны не требуют наличия особых проводящих каналов, а с другой стороны - они могут способствовать возникновению газовых месторождений-гигантов. Одним из основных процессов, определяющих формирование залежей углеводородов, является многофазная фильтрация флюидов (гидротермальные воды, газоконденсат, газ, жидкие углеводороды).

Другой моделью являются двухфазные гравитационно-реверсивные автоколебательные процессы [1-2]. В математическом отношении система уравнений, описывающая такие процессы (в частности, с учётом гравитации), обладает смешанным гиперболически-параболическим типом. Рассмотренная схема предполагает, что движущим механизмов флюидных процессов являются автоколебания в разломах. Они дают некий флюидный импульс, который затем распространяется в массиве вне разлома.

\section{4. Вычислительные эксперименты}

При проведении вычислительных экспериментов по визуализации автоколебательных гравитационно-реверсивных автоколебательных режимов были приняты некоторые предпосылки, упрощающие математические алгоритмы решения. Полагают, что флюид состоит из двух фаз - вода и газ. Все пространство вне разлома вначале заполнено водой. В режиме компакции в разломе из него подается газовый импульс во внешнее (по отношению к разлому) пространство, который распространяется в соответствии с законами двухфазной фильтрации. Структура пористого пространства, в котором распространяется этот импульс, такова: сверху находится соленосная покрышка или пласты с более упругим скелетом или ловушки. Концентрация газового импульса и его движение вверх обеспечивается сложной слоистой структурой трещиновато-пористой среды в подсолевом комплексе. Анализ расчётных баз данных для региона Каракульско-Смушковской зоны и Астраханского свода позволил выделить в подсолевом массиве слоистые комплексы, состоящие из малопроницаемых и сильно проницаемых слоев. Слои с малой проницаемостью образуют своего рода флюидоупоры и способны находиться в метастабильном состоянии. Они частично удерживают газ, но это состояние крайне неустойчиво. Газ все время сочится из этих слоистых комплексов вверх, а когда его накапливается слишком много, то он прорывается и устремляется вверх большими порциями. Объем прорыва зависит от размеров слоистой пачки и числа чередующихся в ней сильно- и малопроницаемых слоев. В исходных предпосылках полагалось, что снизу на определённом уровне находится постоянно действующий линейный источник флюидов, создающий градиент порового давления, которое больше геостатического давления. Разность 
градиентов заставляет нарастающую массу двухфазной смеси флюидов газ вода продвигаться по линиям тока, пока разность порового и геостатического давления не станет равной нулю. В случае двухфазной фильтрации объемные насыщенности фаз $S_{1}$ и $S_{2}$ - доли объема порового пространства, занятые, соответственно, первой и второй фазами: $s_{1}+S_{2}=1$. Закон Дарси для конкретной задачи

$$
\overrightarrow{\mathbf{V}}_{l}=-\frac{k K_{r l}}{\mu}\left(\operatorname{grad} P-\rho_{l} \overrightarrow{\mathbf{g}}\right)
$$

где $\overrightarrow{\mathbf{V}}_{l}$ - скорость фильтрации, $k=k(\overrightarrow{\mathbf{r}})-$ тензор абсолютной проницаемости, $K_{r l}=K_{r l}\left(s_{l}\right)$ - относительные фазовые проницаемости для $l$-го компонента, где $l=w, g$ воды или газа, соответственно, $\rho_{l}(P), \mu_{l}(P)$ - плотности и вязкости флюидов, $\overrightarrow{\mathbf{g}}$ - ускорение свободного падения, $P$ - давление, $\overrightarrow{\mathbf{r}}$ - радиус-вектор. Система уравнений неразрывности[1-2]

$$
\begin{gathered}
\frac{\partial\left(m \rho_{w} s_{w}\right)}{\partial t}=\operatorname{div}\left[\frac{k K_{r w} \rho_{w}}{\mu_{w}}\left(\operatorname{grad} P-\rho_{w} \overrightarrow{\mathbf{g}}\right)-q_{w}\right], \\
\frac{\partial\left(m \rho_{g}\left(1-s_{w}\right)\right)}{\partial t}=\operatorname{div}\left[\frac{k K_{r g} \rho_{g}}{\mu_{g}}\left(\operatorname{grad} P-\rho_{g} \overrightarrow{\mathbf{g}}\right)-q_{g}\right],
\end{gathered}
$$

где $m(\overrightarrow{\mathbf{r}}, p)$ - пористость пласта, $q_{w}, q_{g}$ - объемные расходы флюидов на единицу объема в единицу времени, $s_{w}-$ водонасыщенность, при этом $P$ и $s_{w}-$ независимые переменные.

Система уравнений замыкалась термодинамическими соотношениями. Вода считалась несжимаемой, а газ - идеальным. Уравнение состояния метана

$$
\rho_{g}=\frac{M p}{R T},
$$

где $T$ - температура, которая считалась постоянной, $M$ - молекулярная масса метана, так что $\rho_{g}=c p$, где $c=$ const.

Решение проводилось путём расщепления по процессам: быстрые параболические процессы пьезопроводности (по давлению) и гиперболические процессы переноса водонасыщенности (так называемая сатуриционная часть).

Вычислительные эксперименты строились следующим образом [8]. Предполагалось, что первоначально среда была насыщена только водой. В нижней части области на ее границе задавался ступенчатый во времени первоначальный флюидный поток, содержащий газовую фазу, с амплитудой $4,2 * 10 * * 17 \mathrm{~m}^{3} /$ год. Задавался также более слабый импульс $4,2 * 10^{* *} 16 \mathrm{~m}^{3} /$ год. Он двигался в 7 раз медленнее.

Именно эти численные расчеты движения двухфазного флюида от его источника (разлома) в подсолевом пористом массиве показали, что существуют 
три режима движения флюидов: первичный пробой, реверсивный (колебательный) режим и диссипативный (диффузия в окружающее пространство) процесс. Первичный пробой - это достижение газовой фазой верхних отложений осадочного бассейна, т.е. покрышки. При этом происходит бифуркация решения, и вся динамика флюидов качественно меняется. После этого момента при определенных условиях возникает реверсивный режим, который характеризуется собственными колебаниями. Типичный период цикла в реверсивном режиме состоит в следующем: в начальной фазе происходит накачка флюидов в упомянутую выше слоистую структуру, сопровождающаяся повышением порового давления в этой зоне над гидростатическим давлением. Этот процесс происходит локально, равновесно (градиенты давлений и плотности гравитационных усилий в законе Дарси соизмеримы). Флюидная система перестраивается, накапливая свой потенциал (т.е. объем газа) к пробою сквозь слоистую структуру за счёт повышения давления и увеличения относительной проницаемости газа. Затем начинается связанная с процессом реверсии фаза пробоя, которая состоит в перестройке профиля давлений и всплытия газового пузыря. Всплытие происходит быстро. Необходимо отметить, что в этот период происходит резкое падение давления ниже примерно гидростатического и нарушение локального гидродинамического равновесия в законе Дарси. Собственно динамическая стадия цикла состоит в дальнейшем реверсивном проседании воды в образовавшуюся зону пониженного давления. В завершающей фазе происходит выравнивание (как правило, полное) профилей давлений и флюидной насыщенности, достигая примерно начальных величин цикла. Это и есть третья, асимптотическая стадия цикла.

Наблюдаемые расчётные периоды циклов порядка 50-100 лет. При этом начальный пробой газом всей осадочной толщи происходит примерно за время порядка 300-400 лет [8]. Собственные пространственные и временные масштабы реверсивной флюидной системы, так же как и достижение критической пробойной точки, зависят от флюидного динамического режима всего региона. В частности, они зависят от интенсивности источников поступления углеводородов, генерирующих возможностей системы разломов и термодинамики региона. Придонный источник углеводородов для КаракульскоСмушковской надвиговой зоны на поперечной мощности слоя порядка 50 км задавался в виде ступенчатого по времени газофлюидного потока с амплитудой (общим объёмом газа) порядка $2.85^{*} 10^{2} \mathrm{~m}^{3} /$ сек.

Входные ёмкостные свойства и литологическая информация для расчетов бассейнового анализа (пористости, проницаемости), как правило, бывает недостаточна. Поэтому привлекаются данные бурения по регионам сходного геологического и геодинамического строения, а также данные геофизики. Быстрые прорывы описывались в работе уравнениями изотермической фильтрации двухфазного флюида в среде с упругим скелетом [4]. Краевую задачу о быстрых прорывах решали при условиях, характерных для 
поднадвиговой Каракульско-Смушковской зоны и Астраханского свода. Эта зона аппроксимировалась некоторым телом с простой геометрией, на котором была задана сетка с достаточной степенью точности, отражающая структуру этого района и его литологические и фильтрационные свойства. Расчёты проводились с привлечением системы «Текон». Важная особенность открытых локальных гравитационно-реверсивных автоколебательных режимов состоит в том, что существуют в пространстве коллекторов углеродных бассейнов некие точки. Именно там, особенно если там находится шахта, возможно наступление первичных пробоев. В последующем времени именно в этих местах можно ожидать пробоев газом, в то время как окружающие слоистые пачки коллектора остаются в равновесном стационарном режиме.

Таким образом, при наличии источников образуется флюидный импульс, который встречает на своем пути флюидоупоры и места с повышенной проницаемостью. Формируется профиль давлений. Если флюидоупоров нет, то импульс рассеивается в атмосфере. При этом очень важная для дальнейших выводов об опасности, подстерегающей людей, при разработках больших месторождений, например, угля, гипотеза о существовании одновременно всех форм углеродов в виде твёрдых пород, жидких и газообразных фракций и сопутствующих им процессов. Шахтёры, добывающие уголь, сталкиваются с периодическими процессами заполнения угольных шахт метаном. В воздухе шахты всегда находится угольная пыль, что усугубляет взрывоопасную и пожароопасную ситуацию. Наблюдаемые расчётные периоды циклов - порядка 50-100 лет - вполне соответствуют циклу возможного притока углеводородов на разработанных месторождениях, особенно приуроченных к зонам разломов, что и наблюдают по целому ряду месторождений угля.

\section{Заключение}

На современном этапе развития технологии добычи нефти, газа, угля и других углеводородов особую актуальность приобретает единая концепция математического моделирования, во-первых, строения и поведения недр Земли, во-вторых, изменения горных массивов под воздействием внешних условий, втретьих, происхождения газа и нефти и их циркуляции внутри систем резервуаров, трещин и пор. Математическое моделирование позволяет применить весь арсенал современной вычислительной математики и геоинформатики (сейсмическую съемку, новейшие цифровые карты и другую информацию о Земле с экрана дисплея). Поэтому становится реальным вместо простых моделей традиционной геологии рассматривать более сложные подходы. С помощью компьютерной технологии вычислительного эксперимента развиваются адекватные реальным условиям континуальные теории, учитывающие одновременно множество разнородных факторов, что 
позволяет вести поиск месторождений и их разработку нетрадиционными для геологии методами. Применение вычислительного эксперимента дает возможность проанализировать влияние различных факторов на процессы генерации и миграции углеводородов, оценить запасы в них углеводородов и риски возникновения аварийных ситуаций. Предлагается комплексный подход, заключающийся в создании банка данных сложных моделей, которые помогали бы, с одной стороны, адекватно описывать геодинамическую картину регионов, перспективных для геологоразведочных работ, а с другой - регионов с уже известными объемными источниками. Виртуальная картина, воспроизводящая геологический объект и отражающая неоднородность фильтрационных свойств коллекторов, обусловленную их сложной геометрической и литологической структурой, даст возможность по аналогии с уже имеющимися и хорошо изученными месторождениями в регионах, имеющих похожую геологическую структуру, построить прогноз рисков при разработке. Построение базовой математической модели флюидодинамики требует детального изучения геологических и ландшафтных свойств местности, перспективной для геологоразведочных работ, поскольку риски зависят от конкретного регион. В представляемой работе дана общая геодинамическая схема для изучения таких рисков. Периодически двигаясь вверх и вниз от волноводов и обратно к ним, флюиды создают предпосылки для создания аварийных ситуаций. При движении флюидов в фазе компакции из волноводов вверх они упираются в непроницаемые покрышки и создают аномально высокие пластовые давления. В силу присущей изучаемой пористой упругой среде физической неустойчивости Рэлей-Тейлоровского типа соответствующая математическая нелинейная модель обладает гиперболическими свойствами, развивающиеся асимптотические колебательные процессы в таких средах носят характер градиентных катастроф. Именно этот подход к оценкам опасности при разработке месторождений углеводородов, состоящий в компьютерной технологии прогнозирования флюидодинамических процессов при эволюции осадочных бассейнов и в процессе разработок месторождений, может помочь в прогнозировании спорадических выбросов углеводородов в угольных и других шахтах. В процессе фундаментальных исследований вырабатывались и рекомендации по снижению рисков аварийных ситуаций при разработках угольных и других бассейнов. Становится очевидной необходимость кондиционирования, создания специальных систем шлюзов на поверхность земли для рассеивания газа в атмосфере при чрезвычайной ситуации резкого повышения концентрации метана в шахтах и оборудования для строжайшего контроля изменения концентрации газа.

\section{Библиографический список}

1. Клочкова Л.В., Повещенко Ю.А., Тишкин В.Ф., Самарская Е.А. Математическое моделирование флюидодинамических процессов в земной коре // Computer Sciencies and Telecommunications, 2009, №4, c.6-30 
2. Клочкова Л.В., Повещенко Ю.А., Тишкин В.Ф. Флюидодинамическая модель автоколебательных процессов // Журн. средневолжского математического общества, т.14, №3, 2012, с.8-14.

3. Дмитриевский А.Н., Лобковский Л.И., Казакевич Г.И., Повещенко Ю.А., Баланюк И.Е., Илюхин Л.Н. Численное моделирование движения флюидов в процессе формирования залежей углеводородов на примере Предверхоянского прогиба // Геология, геофизика и разработка нефтяных месторождений, 1995, № 7, с. 2-6.

4. Каракин А.В., Идармачев Ш.Г., Асманов А.А. Фильтрационная модель сезонных изменений сейсмического режима района Чиркейского водохранилища // Физика Земли, 1990, № 6, с. 20-27.

5. Дмитриевский А.Н., Каракин А.В., Баланюк И.Е. Концепцияфлюидного режимав верхней коре (гипотеза корового волновода) // Доклады РАН, 2000, Т. 374, № 4, с. 534-536.

6. Казакевич Г.И., Лобковский Л.И., Пергамент А.Х., Повещенко Ю.А. и др. Математическое моделирование процессов фильтрации углеводородов в осадочных бассейнах // Доклады РАН, 1997, т. 352, № 4, с. 527-531.

7. Казакевич Г.И., Клочкова Л.В., Лобковский Л.И., Минервина Е.А., Пергамент А.Х., Повещенко Ю.А., Самарская Е.А., Соловьев М.С. Метод опорных операторов на нерегулярных сетках в компьютерной технологии прогнозирования при нефте- и газодобыче // Препринты ИПМ им. М.В. Келдыша. 1997. № 23.

8. Казакевич Г.И., Клочкова Л.В., Минервина Е.А., Повещенко Ю.А., Самарская Е.А., Соловьев М.С., Тишкин В.Ф. Процессы миграции углеводородов в реальных геологических регионах // Математическое моделирование, 1998, т. 10, № 6, с. 21-30 


\title{
SAFETY ISSUES IN THE EXPLOITATIONOF SEDIMENTARY BASINS OF HYDROCARBON DEPOSITS
}

\author{
Klochkova L.V., Poveshchenko Yu.A., Tishkin V.F.
}

Numerical simulation of fluid motion in the formation of hydrocarbon deposits allowed to identify complex self-oscillating modes of this process. To describe the motion of liquids and gases in a porous medium, filtration equations are used under the assumption of the feasibility of Darcy's law in the field of gravity, non-mixing phases (for example, gas-water), isothermicity and neglect of capillary forces. It is a complex system of nonlinear partial differential equations. According to one of the variables - pressure - it has properties close to the equations of parabolic type, on the other - saturation - of hyperbolic properties, including - formation of discontinuity surfaces - saturation jumps. The area in which the system is solved, usually has a high degree of heterogeneity, consists of layers with different reservoir properties (porosity, permeability), faults, depositional lithologic discontinuities and other features that complicate as the filtration processes and their numerical modeling. To study such problems, the support operator method provides great opportunities, allowing the use of unstructured grid with cells, the sizes of which may differ by several orders of magnitude. The numerical study by this method revealed that in the problems corresponding to the processes of migration of hydrocarbons in the formation of deposits, self-oscillating gravitational reverse regimes can occur. The characteristic cycle is as follows: the pressure of accumulated gas under a poorly permeable area at some point in time may exceed a critical value. Then there is a gas breakthrough, and if this critical pressure is below the rock strength limit, then the breakthrough does not occur as a result of cracks, but due to the rapid movement of the gas through the site with poor collector properties due to filtration instability. The gas rushes up, the pressure in this area falls, there is a depression funnel, which causes a new influx of gas - until the next critical pressure. 


\section{Оглавление}

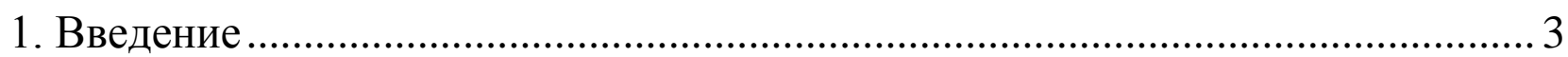

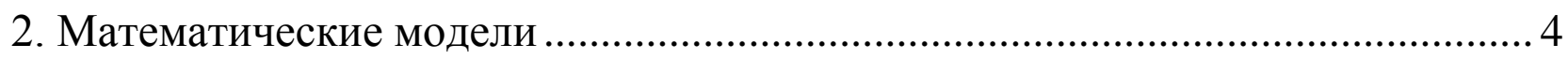

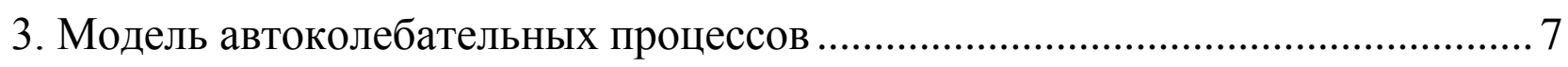

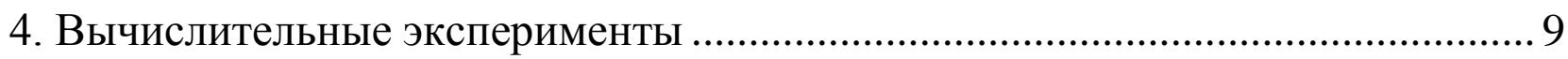

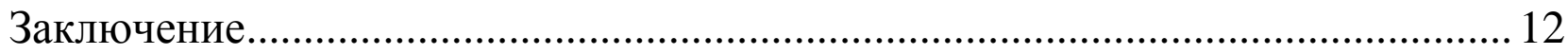

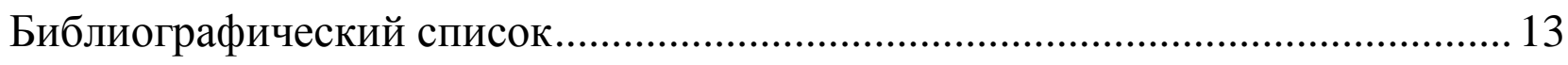

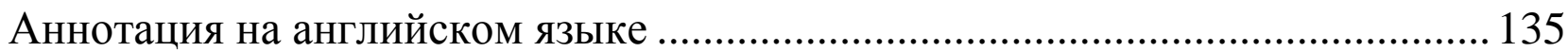

«4» декабря 2018 г. 